\title{
Expression of human cationic trypsinogen (PRSS1) in murine acinar cells promotes pancreatitis and apoptotic cell death
}

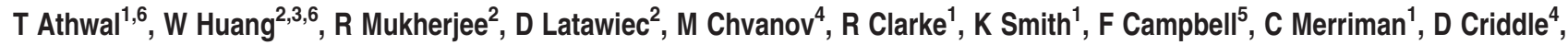 \\ R Sutton ${ }^{1,2}$, J Neoptolemos ${ }^{1,2}$ and N Vlatkovic ${ }^{*, 1}$
}

Hereditary pancreatitis (HP) is an autosomal dominant disease that displays the features of both acute and chronic pancreatitis. Mutations in human cationic trypsinogen (PRSS1) are associated with HP and have provided some insight into the pathogenesis of pancreatitis, but mechanisms responsible for the initiation of pancreatitis have not been elucidated and the role of apoptosis and necrosis has been much debated. However, it has been generally accepted that trypsinogen, prematurely activated within the pancreatic acinar cell, has a major role in the initiation process. Functional studies of HP have been limited by the absence of an experimental system that authentically mimics disease development. We therefore developed a novel transgenic murine model system using wild-type (WT) human PRSS1 or two HP-associated mutants (R122H and N29l) to determine whether expression of human cationic trypsinogen in murine acinar cells promotes pancreatitis. The rat elastase promoter was used to target transgene expression to pancreatic acinar cells in three transgenic strains that were generated: $\mathrm{Tg}(\mathrm{Ela}-\mathrm{PRSS1}) \mathrm{NV}$, $\mathrm{Tg}($ Ela-PRSS1*R122H)NV and $\mathrm{Tg}($ Ela-PRSS1*N29I)NV. Mice were analysed histologically, immunohistochemically and biochemically. We found that transgene expression is restricted to pancreatic acinar cells and transgenic PRSS1 proteins are targeted to the pancreatic secretory pathway. Animals from all transgenic strains developed pancreatitis characterised by acinar cell vacuolisation, inflammatory infiltrates and fibrosis. Transgenic animals also developed more severe pancreatitis upon treatment with low-dose cerulein than controls, displaying significantly higher scores for oedema, inflammation and overall histopathology. Expression of PRSS1, WT or mutant, in acinar cells increased apoptosis in pancreatic tissues and isolated acinar cells. Moreover, studies of isolated acinar cells demonstrated that transgene expression promotes apoptosis rather than necrosis. We therefore conclude that expression of WT or mutant human PRSS1 in murine acinar cells induces apoptosis and is sufficient to promote spontaneous pancreatitis, which is enhanced in response to cellular insult.

Cell Death and Disease (2014) 5, e1165; doi:10.1038/cddis.2014.120; published online 10 April 2014

Subject Category: Experimental Medicine

Hereditary pancreatitis (HP) is characterised by recurrent episodes of acute pancreatitis (AP) that frequently progress to chronic pancreatitis (CP), with exocrine and endocrine insufficiency. ${ }^{1-3} \mathrm{HP}$ is associated with mutations in the human cationic trypsinogen gene (protease serine 1) PRSS1. ${ }^{4}$ Two mutations most frequently found in HP patients are PRSS1 $\mathrm{R} 122 \mathrm{H}$ and N29I. ${ }^{5}$ Biochemical studies have demonstrated that both mutations are associated with a 'gain of function' caused by an increased propensity for trypsin-mediated trypsinogen autoactivation. $^{6,7}$ In addition, $\mathrm{R} 122 \mathrm{H}$ mutation renders trypsin resistant to auto-hydrolysis, resulting in increased protein stability. ${ }^{4,8,9}$ Trypsinogen is an inactive precursor secreted by the acinar cells of the pancreas that is activated by duodenal enterokinase into active trypsin. ${ }^{10}$ Trypsin has a key role in digestion due to its ability to activate itself and other pancreatic digestive enzyme precursors. This has led to the hypothesis that inappropriate intra-acinar activation of trypsinogen initiates a cascade that can overwhelm the protective mechanisms of the acinar cell, such as PSTI (pancreatic secretory trypsin inhibitor or SPINK1), which can inhibit up to $20 \%$ of trypsin activity, ${ }^{11-14}$ resulting in pancreatitis. ${ }^{15,16}$ Once pancreatitis has been initiated, secondary events such as inflammatory cell infiltration, release of pro-inflammatory mediators and cellular death influence the severity of the disease. ${ }^{17-19}$ Experimental models of AP have shown that acinar cell death can occur via both apoptosis and

\footnotetext{
${ }^{1}$ Department of Molecular and Clinical Cancer Medicine, Institute for Translational Medicine, University of Liverpool, Cancer Research Centre, Liverpool, UK; ${ }^{2}$ Liverpool NIHR Pancreas Biomedical Research Unit, Royal Liverpool University Hospital, University of Liverpool, Liverpool, UK; ${ }^{3}$ Sichuan Provincial Pancreatitis Centre, West China Hospital, Sichuan University, Chengdu, China; ${ }^{4}$ Department of Cellular and Molecular Physiology, Institute for Translational Medicine, University of Liverpool, Liverpool, UK and ${ }^{5}$ Department of Pathology, Royal Liverpool University Hospital, Liverpool, UK

${ }^{*}$ Corresponding author: N Vlatković, Department of Molecular and Clinical Cancer Medicine, Institute for Translational Medicine, University of Liverpool, Cancer Research Centre, 200 London Road, Liverpool L4 6TA, UK. Tel: +44 (0)151 794 8810; Fax: +44 (0)151 794 8971; E-mail: vlatko@liverpool.ac.uk

${ }^{6}$ These authors contributed equally to this work.

Keywords: PRSS1; hereditary pancreatitis; transgenic mouse; apoptosis; necrosis

Abbreviations: $\alpha$-SMA, alpha-smooth muscle actin; AP, acute pancreatitis; CP, chronic pancreatitis; HA, haemagglutinin; H\&E, haematoxylin and eosin; $\mathrm{HP}$, hereditary pancreatitis; IHC, immunohistochemistry; SB, Southern blotting; WB, western blotting

Received 16.4.13; revised 17.12.13; accepted 19.12.13; Edited by M Agostini
} 
necrosis, with the latter correlating with a more severe outcome. ${ }^{18,20,21}$ Although intra-acinar activation of trypsinogen has been shown in experimental pancreatitis, the exact mechanism of activation and the role of trypsin in development of pancreatitis remain unclear. In an attempt to investigate the role of trypsinogen in vivo, Archer et al. ${ }^{22}$ developed a model based on acinar-specific expression of a mutated mouse trypsinogen gene, equivalent to the human $\mathrm{R} 122 \mathrm{H}$ mutation, and reported an early onset of acute pancreatic injury with evidence of fibrotic changes with increased age of animals. Another mouse model based on expression of the $\mathrm{R} 122 \mathrm{H}$ mutant of human cationic trypsinogen was also developed; however, these animals failed to develop a spontaneous phenotype possibly due to low transgene expression. ${ }^{23}$ The present study was designed to determine whether expression of wild-type (WT) human cationic trypsinogen, PRSS1, in the murine pancreas would be sufficient to result in spontaneous pancreatitis, or whether expression of mutant forms of PRSS1 (specifically the HPassociated PRSS1 R122H and N29l) would be necessary to promote disease. We have chosen to base our studies on human trypsinogen (PRSS1) for two main reasons: (1) because of its higher propensity to auto-activate ${ }^{24,25}$ compared with other mammalian trypsinogens and (2) because it is unclear which of the known murine trypsinogen genes is the orthologue of PRSS1, the main human trypsinogen, mutation of which can cause HP. We show that animals from all three strains are more prone to developing spontaneous pancreatitis and that this is increased following cerulein challenge. Our data demonstrate that expression of the human PRSS1 gene, whether WT or mutant, predisposes these animals to develop pancreatitis. In addition, our studies suggest that acinar cell apoptosis, rather than necrosis, is associated with transgene expression and thus with the development of pancreatitis in our model system.

\section{Results}

PRSS1 transgenic mice express human PRSS1 in a tissue-specific manner. We generated three transgenic mouse strains $\mathrm{Tg}$ (Ela-PRSS1)NV, Tg(Ela-PRSS1 $\left.{ }^{\star} \mathrm{R} 122 \mathrm{H}\right)$ NVand $\mathrm{Tg}$ (Ela-PRSS1 $\left.{ }^{*} \mathrm{~N} 29 \mathrm{I}\right) \mathrm{NV}$ that express either WT or one of two mutated forms of PRSS1 (R122H and N29I) in the acinar cells of the pancreas by using a rat elastase promoter to target transgene expression. ${ }^{26}$ Hereafter, these strains are referred to collectively as PRSS1 transgenic mice and individually as PRSS1, $\mathrm{R} 122 \mathrm{H}$ and N29l, respectively. Founder mice for each strain were identified by Southern blotting (SB) (Figure 1b), and analysis of transgene expression by western blotting (WB), using an antibody specific for human PRSS1 (AF3848), demonstrated tissue-specific expression of a $32-\mathrm{kDa}$ band corresponding to human PRSS1 that was detectable only in the pancreas and not in other tissues (Figure 1c). Figure 1d shows that all three transgenic strains express comparable levels of the PRSS1 transgenes in the pancreas. The antibody used for these WBs is specific for human PRSS1, showing no crossreactivity to mouse trypsinogen by WB or immunohistochemistry (IHC) analyses (Supplementary Figure 1). We obtained similar results using an haemagglutinin (HA) antibody to detect the transgene product by WB (for example, see Figure 3f). Figure 1e shows immunohistochemical staining typical of all three strains, obtained using a PRSS1-specific antibody, indicating that the transgene is expressed specifically in acinar cells (see also Supplementary Figure 1D). Expression of PRSS1 transgenes, as detected by IHC, was heterogeneous, with some acinar cells exhibiting strong staining, whereas others stained relatively weakly (Figure 1e and Supplementary Figure 2), which is consistent with previous reports of transgene expression from the rat elastase promoter. $^{27}$ Interestingly, we did not observe any substantial difference in the overall expression level between animals homozygous or heterozygous for the transgene by WB or by IHC (Supplementary Figure 2). This might be a consequence of the observed heterogenous expression, suggesting either that each individual acinar cell has a differential ability to regulate the transgene expression level, perhaps due to a feedback regulation process that limits the amount of trypsinogen/trypsin expression, or this could be due to destruction of the most highly expressing acinar cells.

Transgene expression is stable and does not appear to change/diminish with age (Supplementary Figure 2B). All three strains are genetically stable and have continued to express the transgenes for more than 10 generations. Transgenic proteins are part of the pancreatic secretory pathway, since they are present in pancreatic juice collected from animals that express the transgene, but not in WT littermates (Figure 1f). We therefore conclude that the expression of each transgene has been successfully targeted to the acinar cells of the pancreas and, furthermore, that the transgenic proteins are secreted via pancreatic secretory pathways.

PRSS1 transgenic mice display histological and immunohistochemical evidence of pancreatitis. Transgeneexpressing animals demonstrated no gross physical or behavioural differences compared to WT littermates. However, histological examination of the pancreas isolated from transgenic animals revealed pathological changes characteristic of pancreatitis, particularly in ageing ( $>9$ month) animals. Interestingly, these changes occurred spontaneously in up to $10 \%$ of animals expressing all three transgenes (Figure 2). The earliest anomaly seen was vacuolisation present throughout the pancreas of a majority of transgenic animals, often associated with areas of prominent transgene expression (Figures $2 a$ and b). In addition, infiltration of the pancreas by inflammatory cells associated with the loss of adjacent acinar cells was frequently observed and typical examples are shown in Figure 2c. This inflammatory infiltrate coincided with areas in the pancreas where the transgene expression was most visible in the acinar cells (Figure 2d). Some transgenic animals demonstrated a more severe phenotype with large areas of the pancreas replaced by adipocytes (Figure 2e) and a surrounding fibrotic reaction identified by Sirius red staining (Figure 2f). T and B cells, as well as macrophages, often associated with chronic inflammatory lesions, ${ }^{28}$ were frequently present in pancreatic parenchyma (Figures $3 a-c)$. Increased levels of $\alpha$-smooth muscle actin (SMA), an indicator of an active fibrotic process, were observed by $\mathrm{IHC}$ in activated pancreatic stellate cells (Figure $3 \mathrm{~d}$ ) and also 


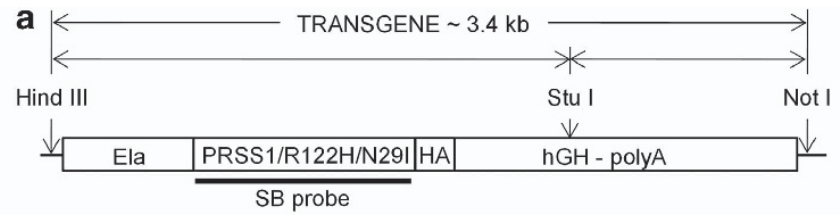

b

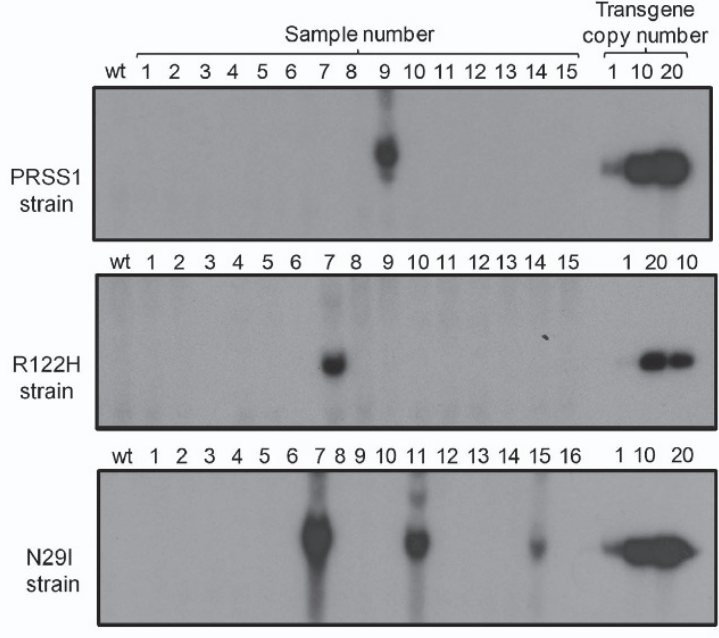

c

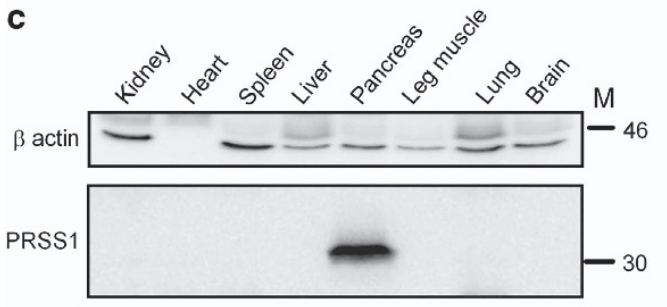

e

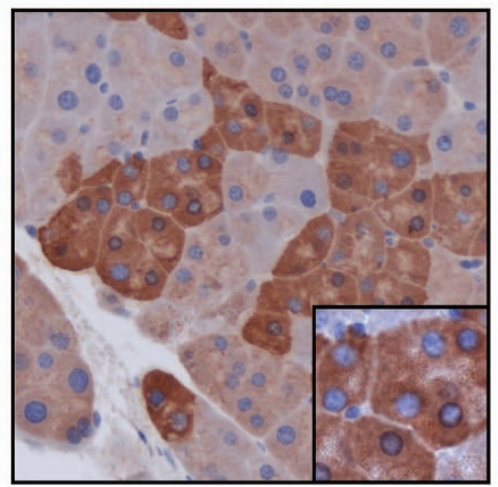

d

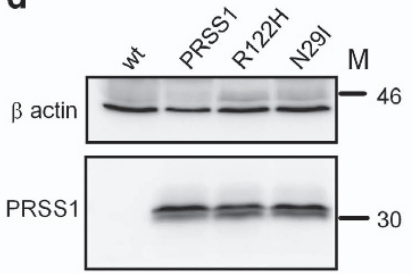

f

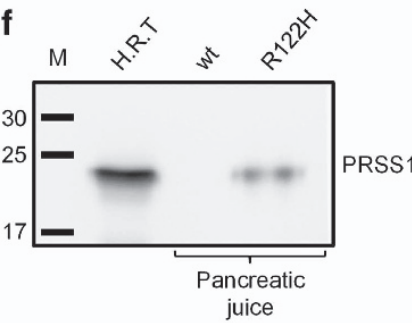

Figure 1 Transgene structure, screening and expression analysis. (a) Schematic representation of transgene constructs used for generation of PRSS1, R122H and N29I strains. Elements labelled are: rat elastase promoter (Ela), cDNA for human PRSS1 gene/mutant R122H or mutant N29l, respectively, with carboxy-terminal haemagglutinin epitope-tag (PRSS1/R122H/N29l-HA), and human growth hormone polyadenylation signal (hGH-polyA). Also indicated are restriction enzyme sites used for generation of transgene (Hindlll and Notl) and in SB screening (Stul) and the location of the probe used for SB. (b) Identification of founder animals for each transgenic strain by SB using the radioactively labelled probe indicated in (a). (c) WB analysis of tissues isolated from a 3-month-old PRSS1 heterozygous animal showing that the transgene is expressed in pancreatic tissue only. (d) WB analysis showing comparable levels of transgene expression in pancreatic tissue isolated from 6-month-old heterozygous animals from each PRSS1 transgenic strain as indicated, compared with WT. For $\mathbf{c}$ and $\mathbf{d}$, samples were probed as indicated with antibodies specific (see Supplementary Figure 1) for PRSS1 (AF3848) or $\beta$ actin (AC-15) as a loading control. (e) Immunohistochemical detection of acinar-specific transgene expression using anti-PRSS1 antibody AF3848. Magnification was $\times 200$. Insert in e shows that transgene is expressed in acinar cell granules. (f) WB analysis showing that the transgene is expressed in pancreatic juice isolated from 6-month-old R122H homozygous animal (R122H), but not in WT animals. H.R.T., human recombinant trypsinogen, used as a positive control. M, molecular weight marker $(\mathrm{kDa})$

by WB in pancreata from animals displaying pancreatitis (Figure 3e). Minor variations in transgene expression observed on WB (Figure 3e) did not correlate with the histological findings of pancreatitis in the transgenic animals. Similar results were obtained for all three transgenic strains and we therefore conclude that transgenic animals 
WT
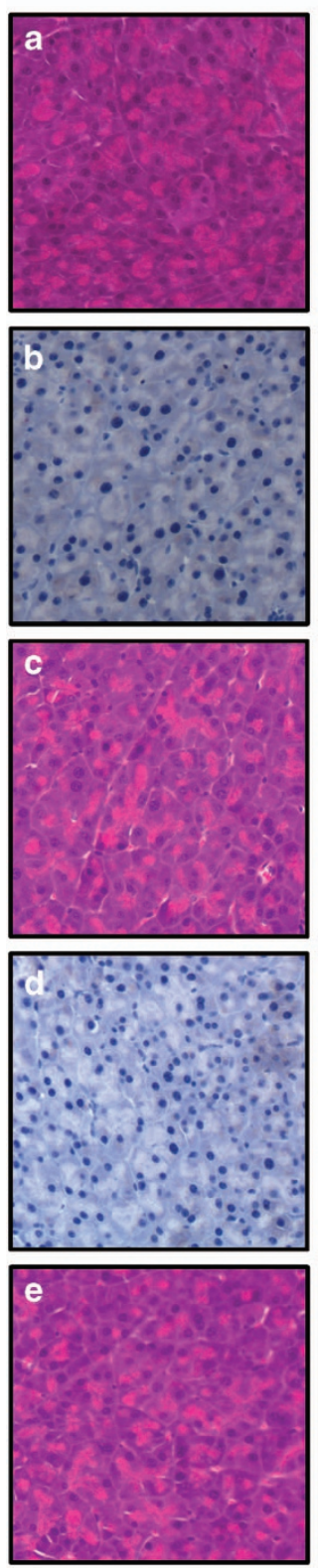

\section{f}

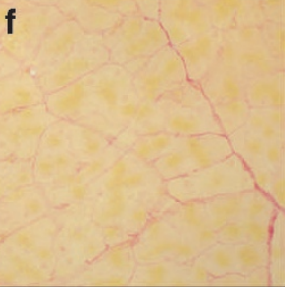

PRSS1
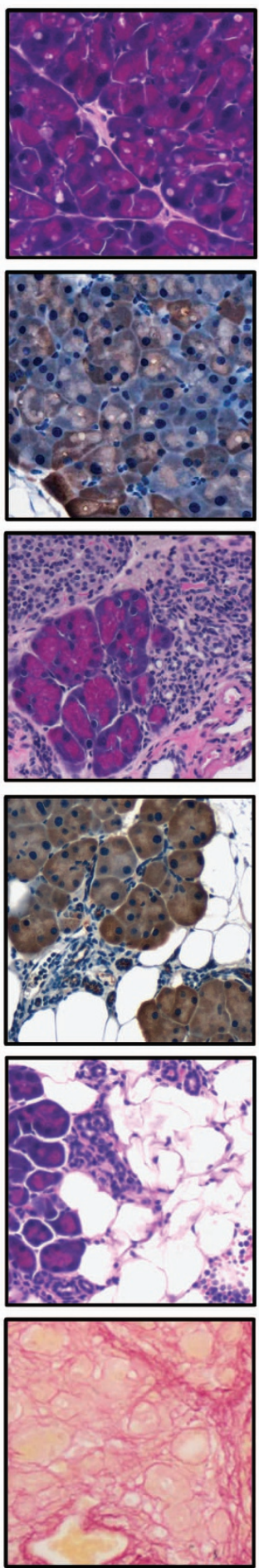

$\mathrm{R} 122 \mathrm{H}$
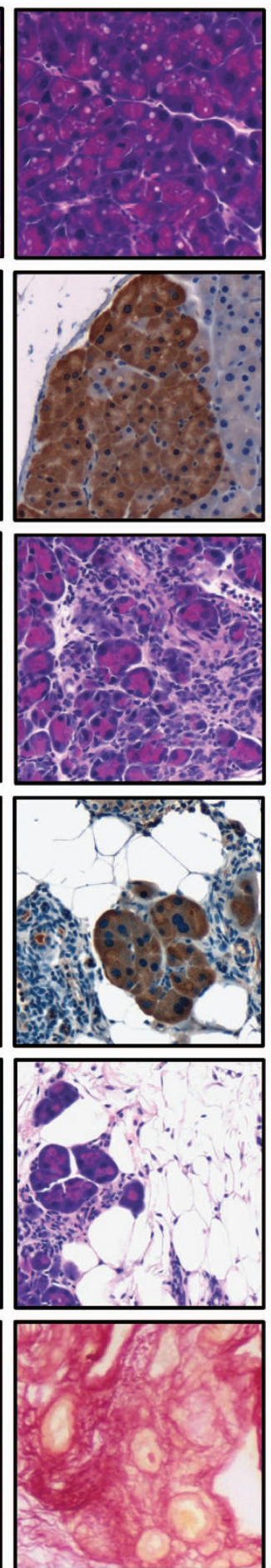

$\mathrm{N} 291$
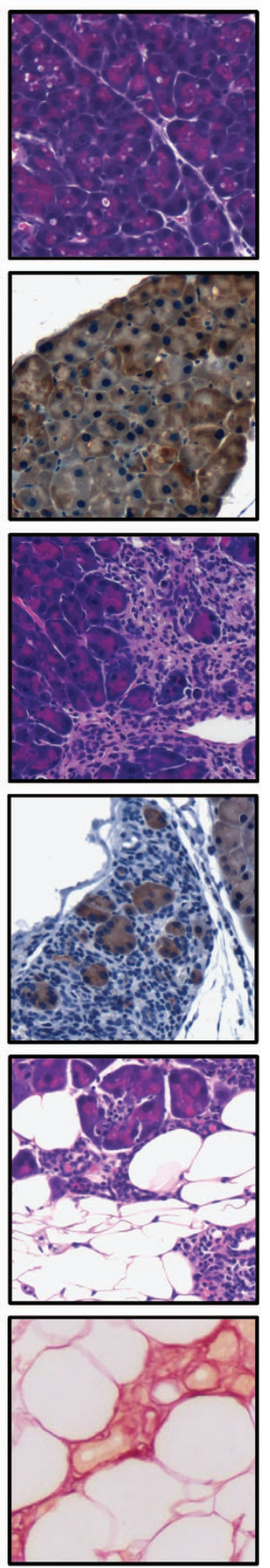

Figure 2 Histological analysis of PRSS1 transgenic animals. (a) Representative images of H\&E-stained tissue sections of pancreatic tissue isolated from 6-month-old heterozygous animals from each transgenic strain, as indicated, showing examples of vacuolisation that was not present in matchedWT control. (b) Immunohistochemical analysis of the animals analysed in (a) using a PRSS1-specific antibody (AF3848) showing co-localisation between vacuolisation and transgene expression and absence of staining in WT control. (c) Representative images of H\&E-stained pancreatic tissue sections isolated from 16-month-old heterozygous animals from each transgenic strain showing infiltration of the pancreas by inflammatory cells associated with the loss of adjacent acinar cells that was not detected in WT control. (d) Immunohistochemical analysis of the same animals analysed in (c) showing that the inflammatory infiltrate coincides with areas of high transgene expression. (e) Representative images of H\&E-stained pancreatic tissue sections isolated from 8-month-old homozygous animals from each transgenic strain showing adipose atrophy that was not detected in WT control. (f) Sirius red staining of pancreatic tissue isolated from 12-month-old heterozygous animals from each transgenic strain, showing collagen deposits (red) in the fibrotic reaction resulting from destruction of acinar tissue that was not detected in WT control. Original magnification $\times 200$ 
WT
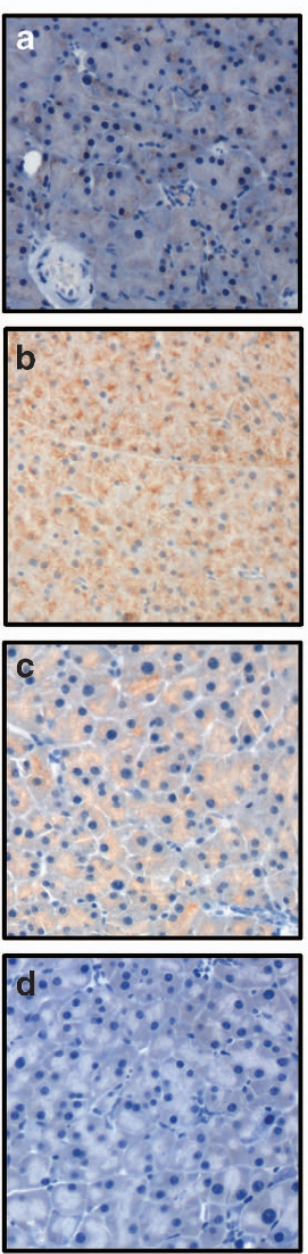

PRSS1
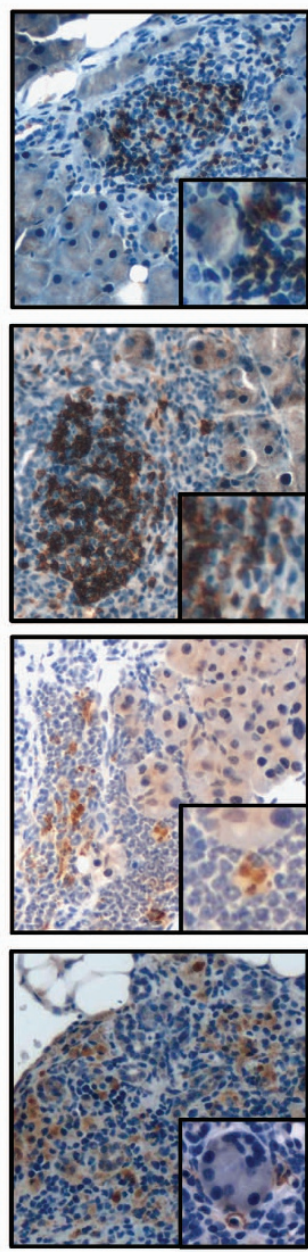

$\mathrm{R} 122 \mathrm{H}$
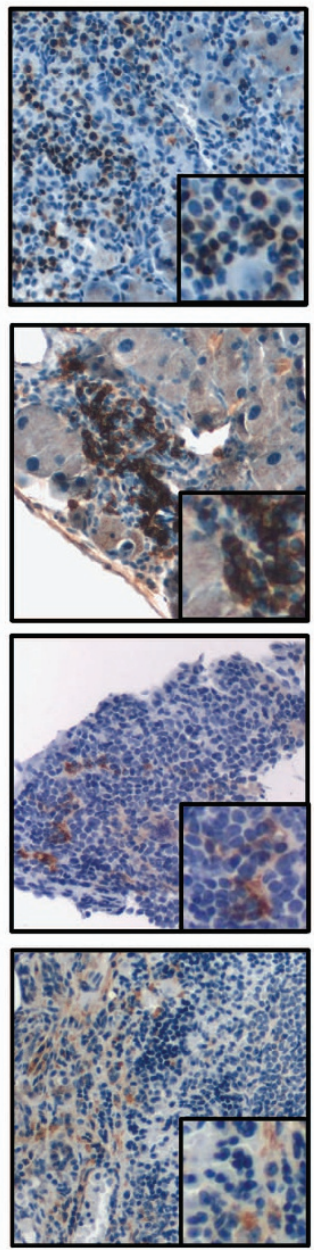

N29
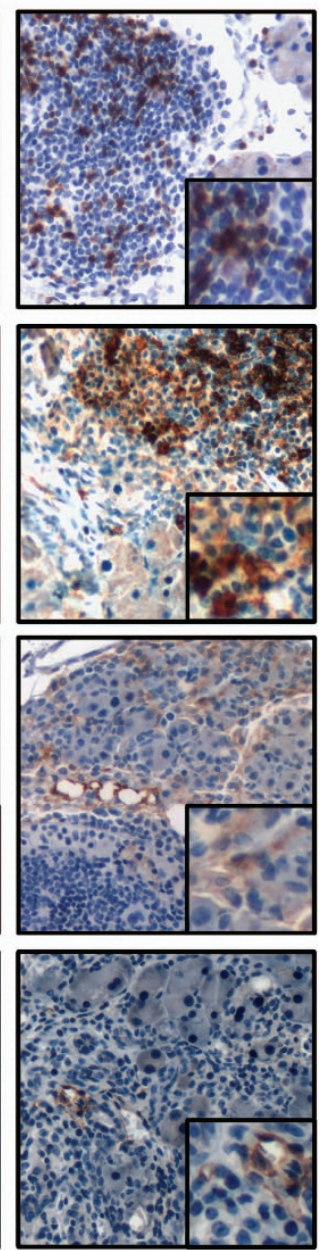

e

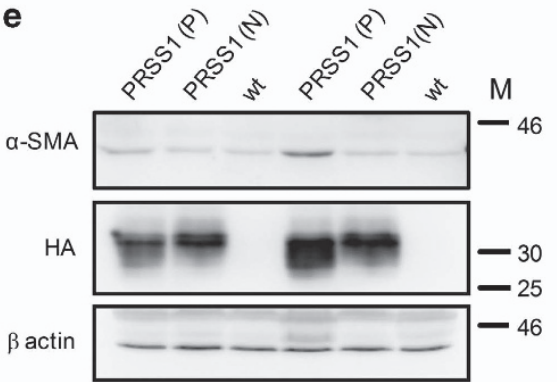

Figure 3 Immunohistochemical analysis of inflammatory lesions observed in pancreatic tissues from PRSS1 transgenic mice. Immunohistochemical analysis of inflammatory infiltrates in 8.5-month-old heterozygous animals from each transgenic strain and age-matched WT control, as indicated, using cell-type-specific marker antibodies for: (a) T cells (CD3), (b) B cells (CD20), (c) macrophages (F4/80) and (d) activated pancreatic stellate cells (PSCs), identified by staining for alpha-smooth muscle actin $(\alpha-S M A)$. Insets represent magnified areas of the photomicrographs (original magnification $\times 200)$. (e) WB analysis of pancreatic tissue isolated from littermates derived from an intercross of PRSS1 heterozygous animals using antibodies specific for $\alpha$-SMA, HA and $\beta$ actin as indicated. Please note that the same blot was probed for SPINK3, shown in Supplementary Figure 3. P = animal with pancreatitis observed by histological analysis; $\mathrm{N}$, histologically normal animal; wt, wild-type animal of the same genetic background; M, molecular weight marker ( $\mathrm{kDa})$

expressing WT human PRSS1 as well as R122H and N29l mutant forms develop pancreatitis characterised by the presence of vacuolisation of the acinar cells, intralobular inflammatory cell infiltrates and fibrosis.

Since not all animals developed pancreatitis spontaneously, we speculated whether increased levels of SPINK1/PSTI expression, an inhibitor of PRSS1, might have a role in the suppression of this phenotype. ${ }^{29}$ Analysis of SPINK3 (the murine homologue of human SPINK1) by WB demonstrated that there was no difference in the expression level between transgenic animals that developed pancreatitis and histologically normal and WT littermates (Supplementary Figure 3), suggesting that SPINK3 levels do not influence development of pancreatitis in our model system. 
Acinar cell architecture is altered by PRSS1 transgene expression. In order to examine the phenotype of acini in more detail, we analysed ultra-thin sections of pancreas tissue by electron microscopy. Marked differences were observed in the appearance of acinar cells from each of the transgenic strains when compared with the WT (Figure 4). The most distinctive feature observed was the presence of enlarged, dilated endoplasmic reticula (DER in Figure 4c). In addition, vacuoles, decondensing zymogen granules and disruption of the apical membranes of acinar cells were observed in each transgenic strain, but not in WT littermates. These data suggest that expression of the WT or mutant human PRSS1 has a detrimental effect on acinar cell architecture.

PRSS1 transgenic mice are sensitised to ceruleininduced pancreatitis. The transgenic mouse strains we generated are prone to developing pancreatitis and therefore we examined whether expression of WT or mutant human PRSS1 would render them more susceptible to chemically induced pancreatitis. Peritoneal injection of cerulein at a supra-physiological dose (typically $50 \mu \mathrm{g} / \mathrm{kg}$ ), has been shown to induce an AP-like phenotype in mice. ${ }^{29,30}$ When this dose of cerulein was administered to WT and PRSS1 transgenic strains, we observed no differences in pancreatic response, with comparable numbers of animals developing pancreatitis from each strain (data not shown). However, when these animals were treated with a lower dose of cerulein $(20 \mu \mathrm{g} / \mathrm{kg})$, transgenic animals from each of the three transgenic strains displayed more severe pancreatitis than WT animals, characterised by pancreatic oedema and infiltration of inflammatory cells, determined through histological analysis (Figure 5a). Quantitative analysis of these parameters ${ }^{31}$ demonstrated that the extent of oedema and inflammatory infiltration and the overall histopathological score (oedema, inflammation and necrosis) in animals from each of the three transgenic strains were significantly higher compared with WT animals (Figures $5 \mathrm{~b}-\mathrm{e}$ ), with $P$ values for WT versus PRSS1/R122H/N29l being respectively: for oedema: $P=0.0064 / 0.0219 / 0.011$, for inflammation: $P=0.0029 / 0.0397 / 0.0017$, and for overall histopathological score: $P=0.0111 / 0.0191 / 0.0038$. With respect to necrosis, only the $\mathrm{R} 122 \mathrm{H}$ strain displayed a statistically significant increase $(P=0.0197)$ following cerulein treatment compared with WT animals (Figure $5 \mathrm{~d}$ ). This suggests that necrosis is not the predominant mode of cell death following the onset of pancreatitis in PRSS1 transgenic mice, since only one strain displays increased necrosis, but all three strains develop
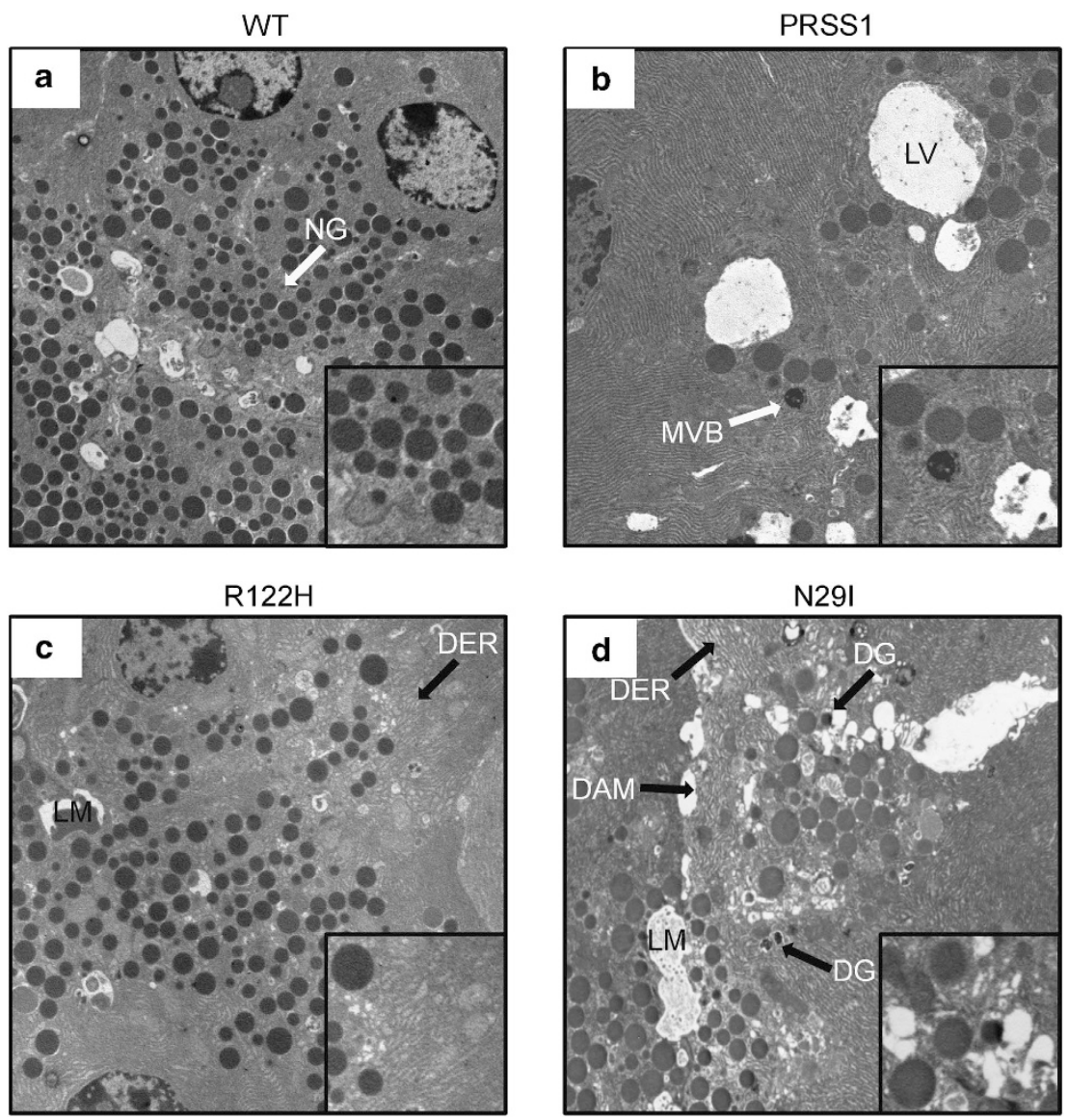

Figure 4 Acinar cell architecture is altered by PRSS1 transgene expression. Pancreatic tissue sections from (a) wild-type (WT), (b) PRSS1, (c) R122H and (d) N29l animals were analysed by electron microscopy. Features characteristic of the disruption of acinar cell cyto-architecture are indicated by arrows and magnified in the inset of each image: normal granules (NG), large vacuoles (LV), multi-vesicular body (MVB), lumen (LM), dilated endoplasmic reticulum (DER), decondensing granule (DG) and disruption of the apical membrane (DAM) 
a

WT

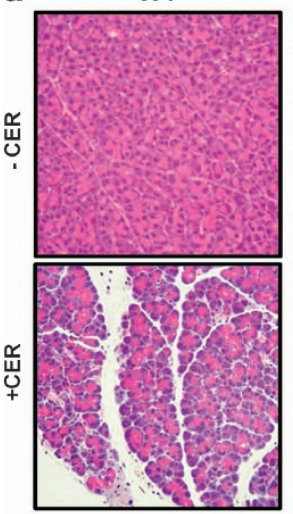

b

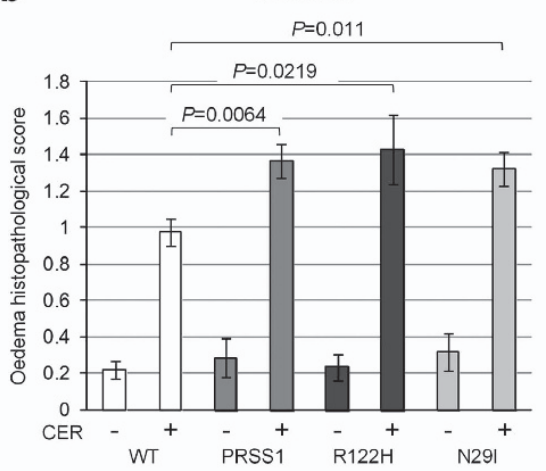

d

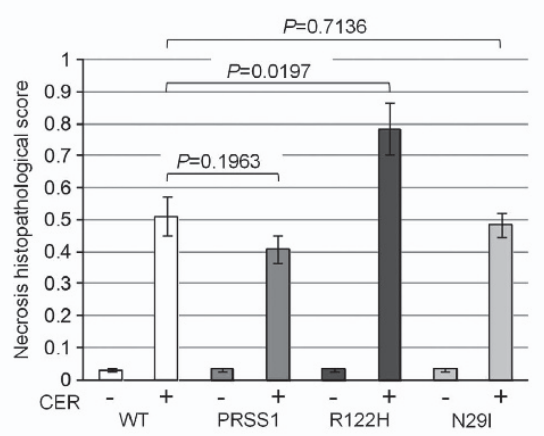

f

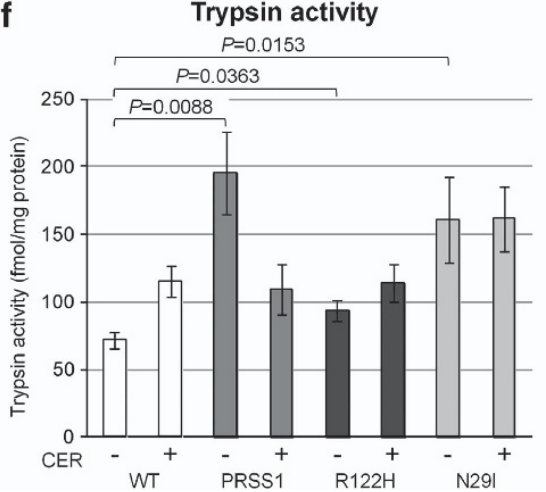

R122H

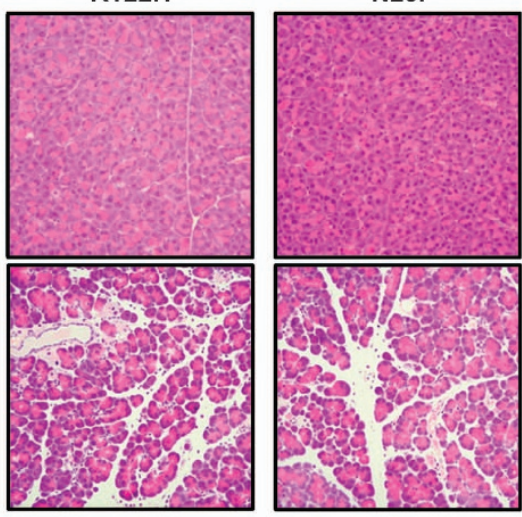

C

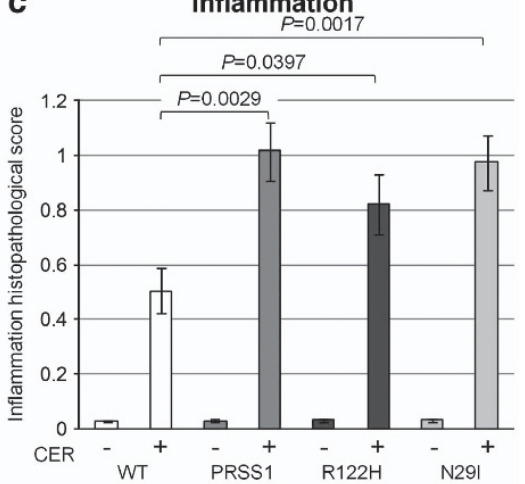

e

Overall score

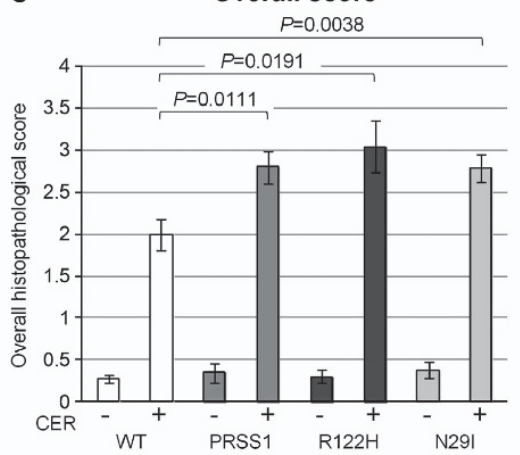

Figure 5 Analysis of cerulein-induced pancreatitis in PRSS1 transgenic mice. (a) Representative images of H\&E-stained tissue sections isolated from animals from each transgenic strain and age-matched WT control, as indicated, in the absence (-CER) and presence ( + CER) of cerulein treatment $(20 \mu \mathrm{g} / \mathrm{kg})$. Original magnification $\times 200$. Histological score examination of WT and transgenic animals for (b) oedema, (c) inflammation, (d) necrosis and (e) overall histopathological score. ${ }^{31}$ (f) Analysis of trypsin activity from pancreata isolated from wild-type and transgenic animals in the absence and presence of cerulein treatment. All animals analysed were 10 months old and derived from intercross mating of heterozygous animals from each transgenic strain as indicated 
pancreatitis comparably. In addition, amylase levels were not significantly different between transgenic and WT animals, both with and without cerulein treatment (Supplementary Figure 4). There is, however, a statistically significant difference between basal levels of trypsin activity (i.e. without cerulein treatment) between each of three transgenic strains and WT animals $(P=0.0088 / 0.0363 / 0.0153$ for the WT versus PRSS1/R122H/N29I, respectively), which disappears following cerulein treatment as Figure $5 f$ shows. It is not clear why there was a reduction in trypsin activity in the PRSS1 animals treated with cerulein compared with the untreated group. Taking these observations together, we conclude that animals from each of the three transgenic strains express higher basal levels of trypsin and thus are primed to develop more severe pancreatitis upon treatment with cerulein than the WT animals, as indicated by the significantly higher score for oedema, inflammation and overall histopathological score.

Acinar cells from PRSS1 transgenic mice display increased apoptosis. There is evidence that the balance between apoptosis and necrosis might determine the severity of AP that occurs in response to acinar cell injury. ${ }^{21}$ Our studies of cerulein-induced pancreatitis demonstrate that there is very little difference in necrosis between transgenic and WT animals, suggesting that changes in necrosis are unlikely to mediate acinar cell death leading to pancreatitis in these animals.

To examine the role of apoptosis in more detail, sections of pancreatic tissue from 9.5-month-old untreated transgenic animals and WT littermates were stained with antibodies specific for a cleaved form of caspase-3, an indicator of apoptosis, $^{32,33}$ and representative images of the $\mathrm{IHC}$ are shown in Figure 6a. Analysis of cleaved caspase-3 staining showed that significantly more cells stained positively in all three of the transgenic strains when compared with WT animals $(P=0.0029 / 0.0014 / 0.0041$ for the WT versus PRSS1/R122H/N29I, respectively) (Figure $6 \mathrm{~b}$ ). In addition, we have also analysed apoptosis using TUNEL assay on pancreatic tissue sections (Figure 6c). Quantification for these assay data confirmed that there were more apoptotic cells in each of our transgenic strains than in WT animals ( $P=0.0071 / 0.0014 / 0.0002$ for the WT versus PRSS1/ $\mathrm{R} 122 \mathrm{H} / \mathrm{N} 29 \mathrm{I}$, respectively) (Figure 6d). Therefore, using two independent methods, we demonstrated that there is more spontaneous apoptosis in pancreatic tissue from each of our transgenic strains, than in a matched WT control. These results suggest that the expression of human PRSS1 in the acinar cells, regardless of whether it is WT or a mutated form, induces an apoptotic response in pancreatic tissue.

To further investigate the response of pancreatic acinar cells to injury, we utilised an in vitro cell death assay in which isolated acinar cells are exposed to the bile acid taurolithocholic acid sulphate (TLC-S) that causes caspase activation resulting in apoptosis. ${ }^{34,35}$ To analyse the apoptotic response, acinar cell clusters isolated from the three transgenic strains or from WT littermate animals were incubated with TLC-S in the presence of R110-aspartic acid amide, a fluorescent indicator-linked caspase substrate. ${ }^{34}$ Propidium iodide staining was used to identify necrotic cells, while Hoechst staining was used to visualise cell nuclei (Figure 7a). As expected, there is a marked increase in the percentage of necrotic and apoptotic cells upon treatment in cells from WT and transgene-expressing animals. However, analysis demonstrates that, with respect to necrosis, acinar cells isolated from each of the three transgenic strains behave in a similar fashion to acinar cells isolated from WT animals (Figure $7 \mathrm{~b}$ ). In contrast, there is a significant increase in the number of apoptotic cells from the three transgene-expressing strains compared with the WT animals, both with TLC-S treatment $(P=0.0249 / 0.0483 / 0.0186$ for the WT versus PRSS1/ $\mathrm{R} 122 \mathrm{H} / \mathrm{N} 29 \mathrm{l}$, respectively) and without $(P=0.0016 / 0.0253 /$ $\left.1.53 \times 10^{-5}\right)$, as shown in Figure $7 \mathrm{c}$. We have also analysed apoptosis in isolated acinar cells using TUNEL assay, and representative images from a typical experiment are shown in Figure 7d. Using this assay, we have observed a statistically significant increase in apoptosis in acinar cells isolated from transgenic animals that were not treated with TLC-S $(P=0.0367 / 0.0174 / 0.0056$ for the WT versus PRSS1/ $\mathrm{R} 122 \mathrm{H} / \mathrm{N29l}$, respectively) (Figure 7e), but not in treated acinar cells. The difference compared with results obtained using the in vitro cell death assay might be a consequence of the different methodology utilised or the fact that animals used for TUNEL assay analysis were young. Regardless, using two independent assays we have demonstrated that there is more spontaneous apoptosis in acinar cells isolated from transgenic animals than in WT ones. Thus we conclude that isolated acinar cells recapitulate the behaviour of in vivo acinar cells in terms of response to cellular injury. In both systems, the mode of acinar cell death that distinguishes samples from pancreatitis-prone PRSS1 transgene-expressing mice from WT mice is apoptosis, not necrosis.

\section{Discussion}

Pancreatitis, whether acute or chronic, is a complex inflammatory disease, with details of the earliest cellular events still to be delineated. ${ }^{36-40}$ While premature, intra-acinar activation of trypsinogen is considered to be one of the initiating events in the pathogenesis of pancreatitis, the in vivo consequences of PRSS1 gene mutations remain unclear. In the present study we have generated three transgenic strains of mice: $\mathrm{Tg}$ (Ela-PRSS1)NV, Tg(Ela-PRSS1 $\left.{ }^{\star} \mathrm{R} 122 \mathrm{H}\right) \mathrm{NV}$ and $\mathrm{Tg}$ (ElaPRSS1*N29I)NV, that express a WT human PRSS1, R122H or N29l mutants, respectively, in the acinar cells of the pancreas. This is the first time that transgenic animals expressing the WT and the two most frequently mutated forms of human cationic trypsinogen detected in HP patients have been generated and analysed. Our data show that each transgene is expressed in a tissue-specific manner restricted to the pancreas, is localised to acinar cells and is part of the pancreatic acinar cell secretory pathway. Moreover, transgene expression in all three transgenic strains analysed does not diminish with the age of animals and has been stable for more than 10 generations. Histological analysis of pancreata isolated from PRSS1 transgene-expressing animals demonstrates that all three strains develop pancreatitis spontaneously, whereas none of their WT littermates do. The pancreatitis that is observed displays major hallmarks of $\mathrm{AP}$ and $\mathrm{CP}$, including vacuolisation, intralobular inflammatory 


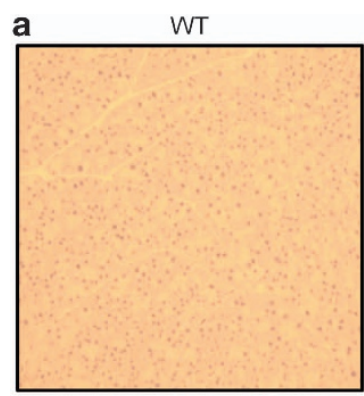

$\mathrm{R} 122 \mathrm{H}$

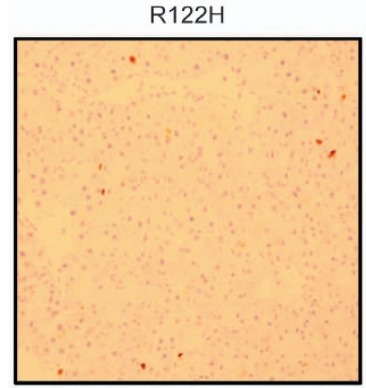

WT

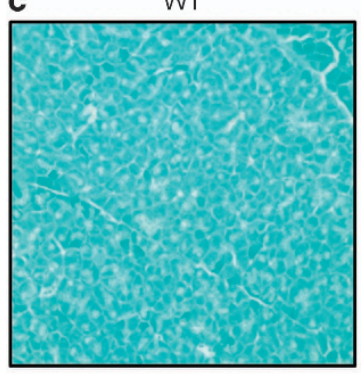

$\mathrm{R} 122 \mathrm{H}$

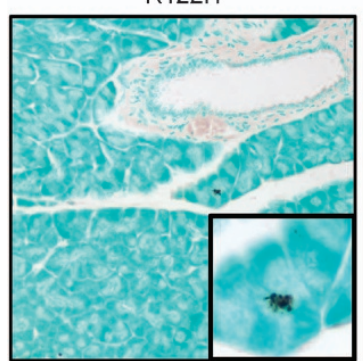

PRSS1

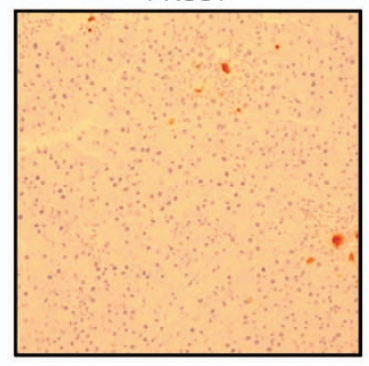

N291

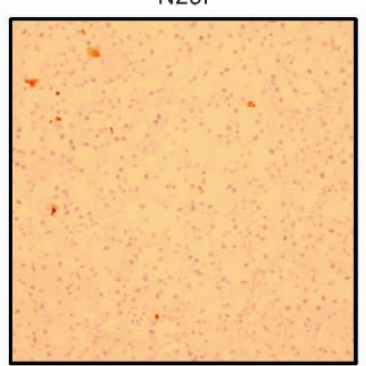

PRSS1

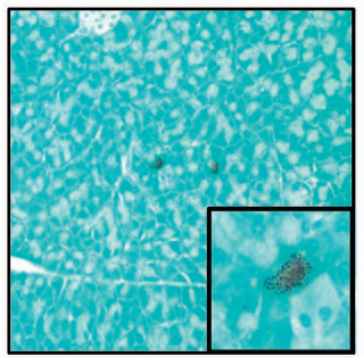

$\mathrm{N} 29 \mid$

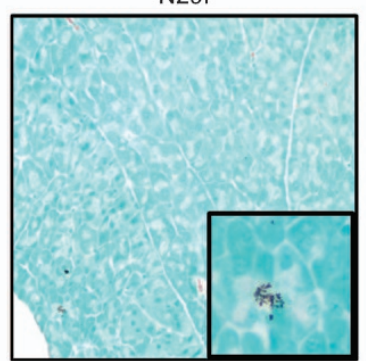

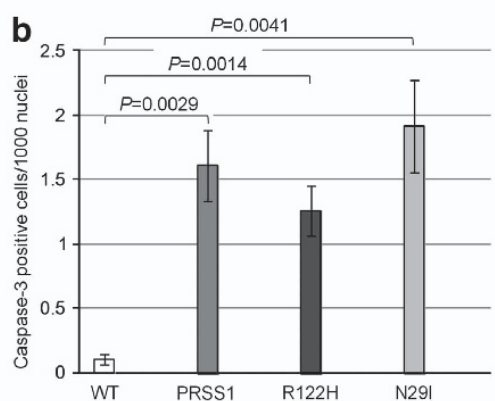
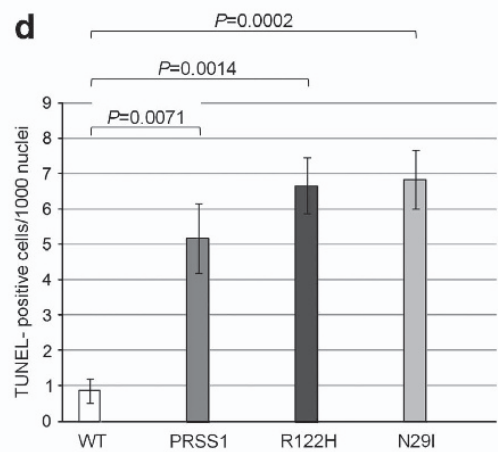

Figure 6 Analysis of cell death in PRSS1 transgenic mice pancreatic tissue sections. (a) Representative images of immunohistochemical analysis of pancreatic tissue sections isolated from animals from each transgenic strain and matched wild-type (WT) control, as indicated, using antibodies specific for cleaved caspase-3. Original magnification $\times 200$. (b) Quantification of immunohistochemical detection of cleaved caspase-3. (c) Representative images of TUNEL analysis of pancreatic tissue sections isolated from animals from each transgenic strain and matched WT control, as indicated. Insets represent magnified areas of the photomicrographs showing punctuate TUNEL-positive staining characteristic of an apoptotic cell (original magnification $\times 200$ ). (d) Quantification of TUNEL assay data

infiltrates containing macrophages, $T$ cells and B cells and fibrosis characterised by the presence of activated pancreatic stellate cells. Examination of pancreatic tissue sections by EM shows that the architecture of the apical region of the acinar cell is disrupted in transgenic animals. These data suggest that pancreas-specific expression of the human PRSS1 gene, regardless of whether it is WT or mutated, promotes pancreatitis and this is the first time that this effect has been observed in an animal model. Clearly, while all of the transgene-expressing animals display pancreatitis following challenge with low-dose cerulein, the incidence of spontaneous pancreatitis indicated incomplete penetrance. One of the possible explanations for the incomplete penetrance seen in transgenic mice might be due to activation of inhibitory or protective mechanisms in acinar cells upon expression of transgenic trypsinogen. It has been suggested that SPINK/PSTI can inhibit up to $20 \%$ of the trypsin activity in the pancreas and transgenic studies have demonstrated that PSTI-I expression can reduce the severity of cerulein-induced pancreatitis. ${ }^{10,12,29}$ In our model system, however, we see no evidence that SPINK has a role in determining the pathophysiology, as the levels of SPINK3 expression are the same in 
a

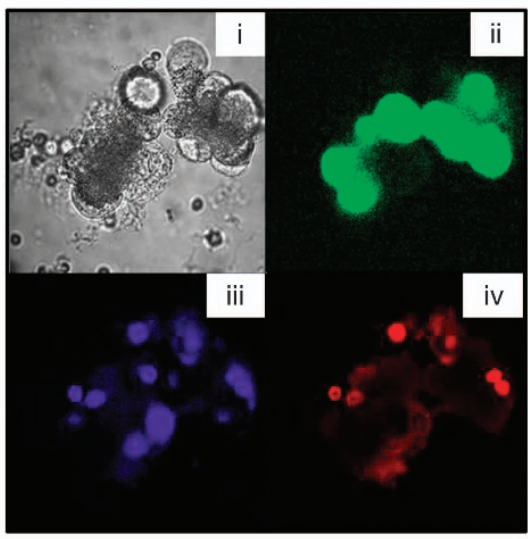

d

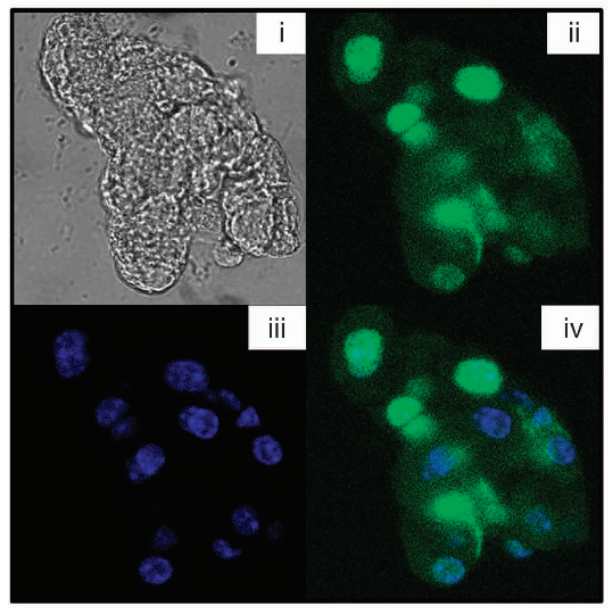

b

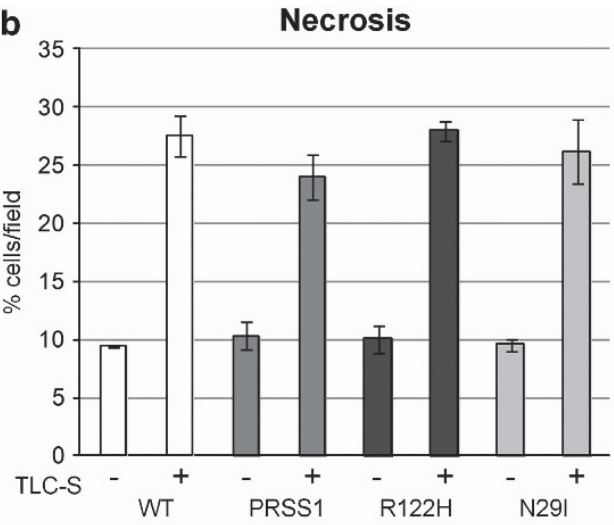

C

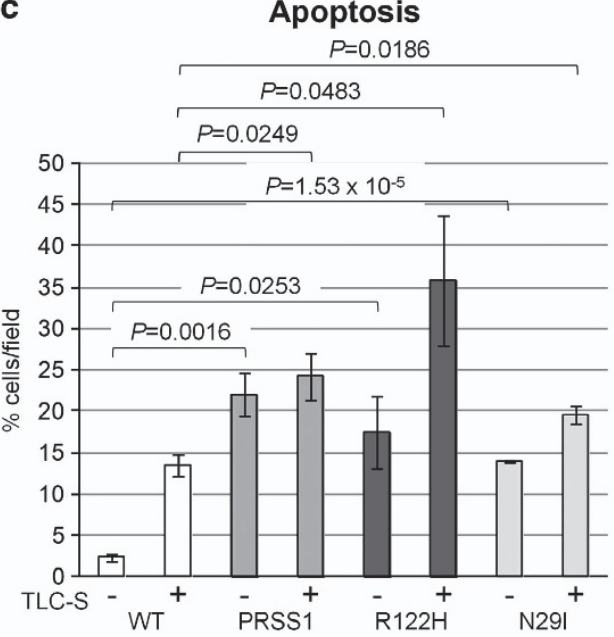

e

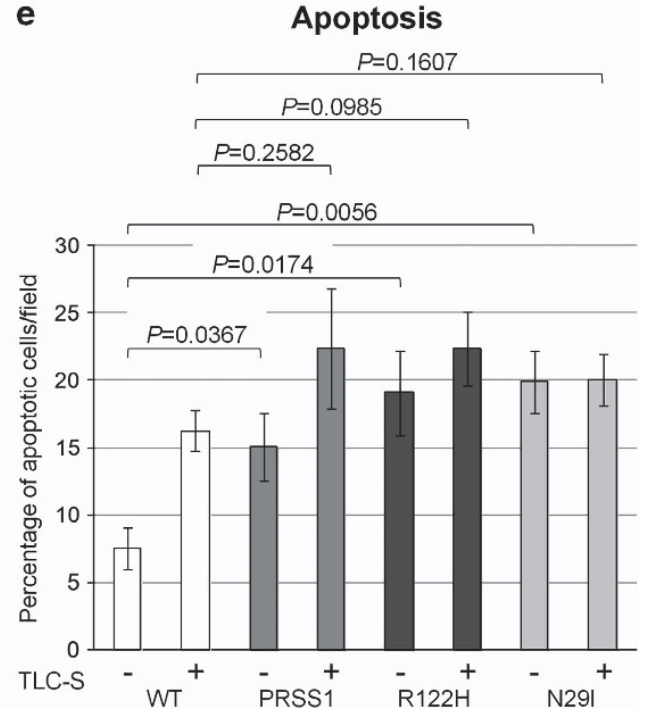

Figure 7 Analysis of cell death in acinar cells isolated from PRSS1 transgenic mice. (a) Representative images from a typical experiment using an in vitro cell death assay ${ }^{34,35}$ to examine isolated acinar cells showing bright field image of cells (i), green fluorescent protein (GFP)-labelled cells with cleaved caspase substrate (ii), nuclei stained with Hoeschst (iii) and necrotic cells stained with propidium iodide (iv). Quantification of necrosis (b) and apoptosis (c) observed in acinar cells isolated from WT and transgenic animals. All animals analysed were approximately 8.5 months old and derived from intercross mating of heterozygous animals from each transgenic strain as indicated. WT animals are littermates negative for the presence of the transgene. (d) Representative images from a typical TUNEL assay performed on isolated acinar showing bright-field image of cells (i), fluorescein-labelled cells using TUNEL assay kit (ii), nuclei stained with Hoeschst (iii) and an overlay of the images shown in ii and iii (iv). (e) Quantification of apoptosis using TUNEL assay performed on isolated acinar cells. All animals analysed were approximately 7 months old and derived from intercross mating of heterozygous animals from each transgenic strain as indicated. WT animals are littermates negative for the presence of the transgene 
transgenic animals with pancreatitis and in histologically normal and WT littermates. An alternative possibility might be the heterogeneous nature of transgene expression driven by the elastase promoter, observed by us and others, ${ }^{27,41,42}$ which, combined with the overall comparable steady-state expression observed in homozygous and heterozygous animals, may suggest either that each individual acinar cell has the ability to regulate the transgene expression levels, or that the pancreas can tolerate only certain levels of trypsinogen expression. This might be due either to some form of feedback regulation or to destruction of the most highly expressing acinar cells, and further studies will be required to examine these questions.

Animals from all three PRSS1 transgenic strains also develop more severe pancreatitis in response to treatment with a low dose $(20 \mu \mathrm{g} / \mathrm{kg})$ of cerulein, and basal trypsin activity, in the absence of cerulein treatment, is significantly higher in the transgene-expressing strains compared to WT littermates. It seems likely that this raised basal trypsin activity may breach a threshold level above which pancreatic damage ensues and is therefore responsible for the increased severity of pancreatitis seen in transgenic animals. This accords with in vivo studies that showed that intra-acinar activation of trypsinogen plays an important role in the initiation of pancreatitis, ${ }^{43,44}$ although a recent study has questioned this in chronic pancreatitis. ${ }^{45}$

Clinically, most cases of AP are mild, self-limiting events that resolve without long-term consequences for the patient; however, $20 \%$ of patients will develop severe AP with evidence of pancreatic necrosis. ${ }^{46}$ The underlying mechanism that drives an episode of AP towards pancreatic necrosis in humans remains poorly understood, though animal models have demonstrated that the apoptosis/necrosis ratio varied significantly depending on the type of model studied. ${ }^{18} \mathrm{We}$ observed significantly higher spontaneous apoptosis in pancreata and in isolated acinar cells isolated from PRSS1 transgenic strains compared with WT animals, suggesting that the expression of human WT or mutated PRSS1 in the acinar cells promotes apoptosis. In contrast, we observed almost no differences in necrosis associated with PRSS1 transgene expression. Therefore, in our model system, apoptosis provides a more likely mechanism of acinar cell death in response to PRSS1 expression. Apoptosis can be a protective mechanism ${ }^{21}$ and it is conceivable that this may be a reason we observed the pathological hallmarks of spontaneous AP in only $10 \%$ of the transgenic animals. A similar protective mechanism may exist in patients with HP, who, despite carrying the disease-causing mutation in PRSS1 from birth, typically exhibit episodes of AP during adolescence. ${ }^{2,3}$ On the other hand, there is evidence that active intra-acinar trypsin may have a protective role in AP. ${ }^{38-40,47}$ However, more recent studies based on genetically modified mouse models accord with our findings showing that intra-acinar trypsinogen activation is implicated in acinar cell death and that this contributes to pancreatic tissue injury that leads to pancreatitis. ${ }^{43,44,48,49}$ Please note that, when using an antibody that crossreacts with human and mouse trypsinogen, the major reactivity detected is the endogenous mouse signal and thus comparatively low levels of human trypsinogen are apparently expressed compared with the endogenous mouse trypsin (Supplementary Figure 1A). This argues against the idea that high levels of transgenic protein, per se, cause pancreatic damage in this system. However, future studies will be needed to address the mechanism in more detail. Thus, it seems most likely that the small, but significant increase in basal trypsin activity that we have observed (Figure 5) is responsible for the phenotype observed in transgenic animals.

It is intriguing that we do not see any difference in phenotype between the three transgenic strains. PRSS1 mutations are associated with HP in humans and it would be expected that expression of mutant forms of human PRSS1 in mouse acinar cells would cause pancreatitis. It was more surprising that transgenic mice expressing wt human PRSS1 also developed pancreatitis spontaneously and are sensitised to low-dose cerulein-induced pancreatitis. One possible explanation for this might be a higher propensity of human cationic trypsinogen to auto-activate compared to trypsinogens from other species. ${ }^{25}$ As mouse acinar cells have evolved to regulate a less intrinsically auto-activateable form of trypsinogen, it is likely that expression of wt human PRSS1 in murine acinar cells leads to an imbalance in the normal regulation of trypsinogen activity. This conclusion is supported by a significant increase in basal trypsin activity that we have observed in animals expressing wt PRSS1 (Figure 5).

In conclusion, our findings shed a new light on the role of PRSS1 in acinar response to cellular injury and development of pancreatitis. We have established that expression of human PRSS1 in mouse acinar cells, regardless of whether in WT or mutated form, can promote spontaneous pancreatitis and also increase sensitivity to cerulein-induced pancreatitis. The PRSS1 transgenic strains we have generated may therefore provide useful models for studying early events in pancreatitis, as well an opportunity for developing a preclinical testing platform for novel therapeutic approaches.

\section{Materials and Methods}

Construction of transgenes. The first-strand CDNA of WT human PRSS1 (OMIM \#276000) was generated by reverse transcription polymerase chain reaction from total human pancreas RNA (Ambion/Life Technologies Ltd., Paisley, UK) using the primer $5^{\prime}$-ACCATGAATCCACTCCTGATCCTT- $3^{\prime}$. This strand was used as the template for PCR synthesis of human PRSS1 cDNA using the following set of primers: 5 -GAGAGGATCCCACCATGAATCCACTCCTGATCCTT$3^{\prime}$ and $5^{\prime}$-GAGAGGATCCTCAAAGAGCGTAATCTGGAACATCGTATGGGTAGC TATTGGCAGCTATGGTGTTC- $3^{\prime}$ that introduced a BamHI restriction site at the $5^{\prime}$ terminus and a $\mathrm{HA}$ tag sequence with $\mathrm{BamHI}$ restriction site at the $3^{\prime}$ terminus. This PCR product was subcloned into a vector containing the acinar-specific control region $(-500$ to +8$)$ of the rat elastase I gene and also the human growth hormone (hGH) $3^{\prime}$ untranslated region (UTR) $(+500$ to +2657$)$ (a kind gift from Raul Urrutia). The R122H and N29l mutants were generated by PCR mutagenesis using the wtPRSS1 cDNA as the template. The R122H mutation was generated by using a pair of overlapping primers $5^{\prime}$-CGCCCACGTGTCCAC CATCTCTCTGCCCACCGCCCCTCCAGCCACTGGCA-3' and $5^{\prime}$-TGCCAGTGG CTGGAGGGGCGGTGGGCAGAGAGATGGTGGACACGTGGGCG-3', in combination with primers used for the generation of the wtPRSS1 construct described above. The two resulting PCR products were annealed and used as the template for a final PCR product containing the $\mathrm{R} 122 \mathrm{H}$ mutation and also a BamHI site at the $5^{\prime}$ terminus and a HA-tag with BamHI site at the $3^{\prime}$ terminus. The N29l mutation was generated using the primer $5^{\prime}$-GAGAGGATCCCACCATGAATC CACTCCTGATCCTTACCTTTGTGGCAGCTGCTCTTGCTGCCCCCTTTGATGAT GATGACAAGATCGTTGGGGGCTACATCTGTGAG- $3^{\prime}$ in combination with one of the primers used for the generation of the wtPRSS1 construct described above. All plasmid constructs were sequenced to confirm their identity (Eurofins MWG Operon, London, UK). 
Generation of transgenic mice. Transgenic strains were generated at the University of Liverpool Transgenic Unit. Animal experiments were performed with appropriate approval and licences from the United Kingdom Home Office under the guidelines approved by the University of Liverpool. Mice were housed in cages in climate-controlled rooms with an ambient temperature of $23 \pm 2{ }^{\circ} \mathrm{C}$ with a $12: 12 \mathrm{~h}$ light-dark cycle. They were fed standard laboratory chow with access to water ad libitum. Each transgene was generated by Hindll and Notl digestion of the transgenic constructs shown in Figure 1a. The resulting 3.4-kb fragment containing the elastase promoter, the human wtPRSS1 (or one of the mutant alleles) and the human growth hormone polyadenylation signal was microinjected into pronuclei of zygotes isolated from C57B//CBA F1 hybrid mice. At least two founder animals for each transgenic strain ( $\mathrm{Tg}$ (Ela-PRSS1)NV, Tg(ElaPRSS1*R122H)NV and Tg(Ela-PRSS1*N29I)NV) were identified by SB analysis, performed essentially as described previously, ${ }^{50}$ using a probe specific for the human PRSS1 sequence (indicated in Figure 1a). The transgene copy number for each founder was estimated using SB by comparison with the appropriate transgene copy number controls as shown in Figure $1 b$. The founders that displayed one major band, the size of the transgene and only one additional band in SB, suggestive of a single integration site (for example, number 9 for PRSS1 strain, number 7 for R122H strain and number 11 for N29l strain), were chosen for further breeding. SB analysis performed on animals from several consecutive generations displayed the same banding pattern, indicating that each transgenic line was genetically stable and suggesting that the integrations occurred at single loci. We maintained heterozygous inter-crosses for each strain throughout the project to generate littermates for further analysis, but also to identify potential homozygous animals that were confirmed to be homozygous by repeated matings onto the C57BI6 background (all offsprings were positive for the presence of transgene (i.e., they were heterozygous)). Once a stable transgenic line was established for each strain, PCR analysis was used for routine screening of the animals using the following primers: $5^{\prime}$-GAGAGGATCCTCAAAGAGCGTAATCTG GAACATCGT $-3^{\prime}$ and $5^{\prime}$-GAGAGGATCCCACCATGAATCCACTCCTGATCCTT- $3^{\prime}$. Unless otherwise stated, age-matched transgenic mice were compared with mice of the same genetic background (littermates) lacking the transgene, referred to as WT.

Western blot analysis. Proteins were extracted from tissue samples using the procedures described previously. ${ }^{27}$ Briefly, snap-frozen tissue samples were homogenised under liquid nitrogen using a pestle and mortar. The homogenised tissue was resuspended in buffer containing $20 \mathrm{mM} \mathrm{HEPES}, 25 \%$ glycerol, $0.42 \mathrm{M}$ $\mathrm{NaCl}, 1.5 \mathrm{mM} \mathrm{MgCl}, 0.2 \mathrm{mM}$ EDTA, $1 \mathrm{mM}$ DTT, $1 \mathrm{mM}$ PMSF and the following protease inhibitors: aprotinin $(2 \mu \mathrm{g} / \mathrm{ml})$, leupeptin $(0.5 \mu \mathrm{g} / \mathrm{ml})$, pepstatin A $(1 \mu \mathrm{g} / \mathrm{ml})$ and soybean trypsin inhibitor $(100 \mu \mathrm{g} / \mathrm{ml})$, subjected to three freeze/thaw cycles, and then following clarification by centrifugation the supernatant was collected as the total protein extract. For western blot analysis, typically $50 \mu \mathrm{g}$ of total protein was separated by SDS-PAGE, transferred onto Hybond ECL nitrocellulose membrane (GE Healthcare, Little Chalfont, UK), probed with specific antibodies and the signal detected by Western Lightning chemilluminescence reagent (Perkin Elmer, Cambridge, UK) as described previously. ${ }^{51}$ The antibodies used recognised as follows: HA: $16 \mathrm{~B} 12$ (Cambridge Biosciences, Cambridge, UK), human PRSS1: AF3848 (R\&D Systems, Abingdon, UK), $\beta$ actin: AC-15 (Sigma, Poole, UK), $\alpha$-tubulin DM1A (Sigma), $\alpha$-smooth muscle actin: ab 5694 (Abcam, Cambridge, UK) and SPINK3 (kind gift from Walter Halangk).

Histological and immunohistochemical analysis. Mice were killed at the specified times or upon onset of apparent signs of morbidity. Tissue samples were fixed in $10 \%$ formalin and embedded in paraffin, sectioned at $5 \mu \mathrm{m}$ and processed for haematoxylin and eosin (H\&E) staining. The slides were coded and submitted to a blind grading of the severity of pancreatitis, with concordance among two individual investigators. ${ }^{31}$ Sirius red staining for collagen was performed to evaluate the extent of fibrosis, as previously described. ${ }^{52}$ Immunohistochemical staining was performed using primary antibodies specific for human PRSS1: AF3848 (R\&D Systems), CD3: MCA1477 (AbD Serotec, Oxford, UK), CD20: M-20 (Santa Cruz Biotechnology Inc., Heidelberg, Germany), smooth muscle actin: 1AF (Sigma), F4/80: A3-1 (Abcam) and cleaved Caspase-3 (Cell Signaling Technology, Danvers, MA, USA). Unless stated otherwise, antigen retrieval was performed by boiling slides in citrate buffer ( $10 \mathrm{mM}$ citric acid, $\mathrm{pH} 6.0)$ or Tris-EDTA buffer (10 mM Tris base, $1 \mathrm{mM}$ EDTA, $0.05 \%$ Tween $20, \mathrm{pH} 9.0$ ) for $15 \mathrm{~min}$. Primary antibodies and biotinylated secondary antibodies were diluted in $2.5 \%$ normal serum in PBS and incubated for $30 \mathrm{~min}$ at room temperature. Following this the slides were incubated with Vectastain $A B C$ reagent and $D A B$ peroxidise substrate kit (both from Vector Laboratories Ltd., Peterborough, UK), counterstained with haematoxylin and mounted for viewing.

Electron microscopy. For electron microscopy, thinly sliced sections of the pancreas ( $\sim 1 \mathrm{~mm}$ thick) were fixed for $1 \mathrm{~h}$ in $4 \%(\mathrm{w} / \mathrm{v})$ paraformaldehyde and $2.5 \%$ (v/v) glutaraldehyde (both from Sigma) at room temperature before additional fixation in $1 \%(\mathrm{w} / \mathrm{v})$ osmium tetroxide and further staining in $0.5 \%(\mathrm{w} / \mathrm{v})$ uranyl acetate (both from TAAB Laboratory Equipment Ltd, Reading, UK). The sections were then dehydrated through a series of graded ethanol concentrations, before flat embedding in Agar 100 epoxy resin. After polymerising for 2 days, ultrathin sections $(60-80 \mathrm{~nm})$ were cut on a Leica EM UC6 ultramicrotome and transferred onto formvar-coated $200 \mu \mathrm{m}$ mesh copper grids (Agar Scientific, Stansted, UK). These were counterstained with $4 \%$ uranyl acetate and Reynolds lead citrate before visualisation at $100 \mathrm{kV}$ on a FEI Technai $120 \mathrm{KV}$ G2 Spirit BioTWIN electron microscope (FEI, Eindhoven, The Netherlands). Digital images were taken up to $\times 87000$ magnification and captured using a SIS Megaview III camera (Olympus, Hamburg, Germany) and analysed using AnalySIS Pro software (Olympus).

Induction of pancreatitis by cerulein treatment. For induction of pancreatitis, approximately 10-month-old transgenic or WT animals of the same genetic background (5-10 animals per experimental group) were fasted for 12$16 \mathrm{~h}$ before each experiment with free access to water. Mice were administered hourly seven consecutive intraperitoneal injections of the pancreatic secretagogue cerulein (Sigma) at a dose of 20 or $50 \mu \mathrm{g} / \mathrm{kg}$ as indicated. Animals were killed $12 \mathrm{~h}$ after the first injection. Blood samples were obtained by cardiac puncture for serum amylase determination and the pancreata removed, weighed and fixed in formalin for H\&E staining and histological examination. To assess the severity of cerulein-induced pancreatitis, H\&E-stained tissue sections from all experimental groups were graded by two blinded independent observers, using the method described previously. ${ }^{31}$ Briefly, for each parameter (oedema, inflammatory cell infiltrate and necrosis) ten fields were randomly chosen, scored and the average score was used for data analysis. The overall histopathological score was calculated as the sum of these three parameters, with each contributing equally to the total score.

In vitro cell death assay. In vitro cell death assay was performed essentially as described previously. ${ }^{53}$ Briefly, fresh pancreatic acinar cells were isolated with collagenase as described previously, ${ }^{54}$ either treated or not with TLC$\mathrm{S}$ for $30 \mathrm{~min}$ and activation of the apoptotic pathway was detected with rhodamine $110 /$ aspartic acid amide $(20 \mu \mathrm{mol} / \mathrm{l})$, a fluorescent indicator-linked general caspase substrate. ${ }^{34}$ Plasma membrane rupture, characteristic of necrosis, was detected by staining with propidium iodide ( $\mathrm{Pl} ; 1 \mu \mathrm{mol} / \mathrm{l})$, while nuclei were visualised with Hoechst $33342(50 \mu \mathrm{g} / \mathrm{ml})$. Fluorescence of R110/aspartic acid amide (excitation 488 and emission > $505 \mathrm{~nm}$ ), PI (excitation 488 and emission 630-693 nm), and Hoechst 33342 (excitation 364 and emission $405-450 \mathrm{~nm}$ ) was recorded using a 63x C-Apochromat objective (Carl Zeiss Jena GmbH, Jena, Germany). Thirty highpower fields from each experiment were scored, repeated in triplicate. The total number of necrotic or apoptotic cells counted per field was then used to calculate the percentage of necrosis/apoptosis for each field, which was then averaged across all fields.

Analysis of apoptosis using TUNEL assay. Fresh pancreatic acinar cells were isolated with collagenase as described previously. ${ }^{54}$ Cells obtained from each mouse were divided into one group that was treated with TLC-S and another group that was not. Following this, cells were plated onto three glass coverslips per group per mouse. Cells were fixed in freshly prepared $4 \%$ paraformaldehyde in PBS and permealised on ice for 5 min using permeabilisation solution $(0.5 \%$ triton $\mathrm{X}-100$ in $0.1 \%$ sodium-citrate). TUNEL assay was performed using In Situ Cell Death Detection Kit with Fluorescein (Roche Applied Sciences, Burgess Hill, UK) following the manufacturer's protocol. After TUNEL staining, cells were also stained with Hoescht and coverslips mounted onto slides for analysis. Cells were analysed on a Leica SP2 AOBS confocal microscope (Leica Microsystems, Milton Keynes, UK) and the percentage of apoptotic cells was counted. A cell was considered apoptotic if it had either a TUNEL-positive nucleus or had bright TUNEL-positive vacuole-like round structure(s) originating from nucleus. Sequential $405 \mathrm{~nm}$ excitation/420-470 nm emission and $496 \mathrm{~nm}$ excitation/ 510-550 emission was used for Hoescht and fluorescein-tagged TUNEL imaging, respectively. 
TUNEL assay analysis of pancreatic tissue sections ( 6 animals per each group of animals that were analysed, two tissue sections per each animal) was performed using TACS $^{\mathrm{R}} 2$ TdT-DAB In Situ Apoptosis Detection Kit (Trevigen Inc., Gaithersburg, MD, USA) following the manufacturer's protocol. Briefly, paraffinembedded pancreas tissue was sliced into $6 \mu \mathrm{m}$ thick sections and mounted onto pretreated slides. Sections were then deparaffinised, TUNEL stained and counterstained in Methyl Green before coverslips were being mounted. The number of positive TUNEL-stained cells per tissue section was determined using Nikon E-800 Eclipse microscope (Nikon, Kingston Upon Thames, UK) and images taken using SPOT RT Colour camera with Metamorph Software (Molecular Devices, Sunnyvale, CA, USA).

Statistical analysis. Results were expressed as mean \pm standard error of the mean from multiple separate experiments. Statistical analysis was performed using $t$-tests with SPSS version 16 software (IBM, Portsmouth, UK). Statistical significance was set at $P$ values $<0.05$

\section{Conflict of Interest}

The authors declare no conflict of interest.

Acknowledgements. We are extremely grateful to Professor Mark Boyd for numerous helpful discussions and also thank Mark Boyd, Drs Carlos Rubbi and Eithne Costello, and Professor Graham Dockray FRS for critically reviewing the manuscript. We are very grateful for the technical support from Dr Kerryanne Crawford and members of the Liverpool BSU, especially Barry Cotterill. This work was partly funded by a grant to NV and JPN from the Royal Liverpool University Hospital R and D Fund, National Institute for Health Research grant to the NIHR Liverpool Pancreas Biomedical Research Unit; MC has been supported by an MRC grant to Professor A. Tepikin.

\section{Author Contributions}

TA and WH acquisition, analysis and interpretation of data and preparation of manuscript; RM, DL and MC: acquisition, analysis and interpretation of data; $\mathrm{RC}$ and KS: technical support for the study; FC: analysis and interpretation of data; CM: acquisition of data; DC: student supervision; RS: study concept and design; $\mathrm{JN}$ : study concept and design, material support and preparation of manuscript; NV: study concept and design, acquisition, analysis and interpretation of data, preparation of manuscript and supervision of the study.

1. Applebaum-Shapiro SE, Finch R, Pfutzer RH, Hepp LA, Gates L, Amann S et al. Hereditary pancreatitis in North America: the Pittsburgh-Midwest Multi-Center Pancreatic Study Group Study. Pancreatology 2001; 1: 439-443.

2. Howes N, Lerch MM, Greenhalf W, Stocken DD, Ellis I, Simon P et al. Clinical and genetic characteristics of hereditary pancreatitis in Europe. Clin Gastroenterol Hepatol 2004; 2 252-261

3. Rebours V, Boutron-Ruault MC, Schnee M, Ferec C, Le Marechal C, Hentic O et al. The natural history of hereditary pancreatitis: a national series. Gut 2009; 58: 97-103.

4. Whitcomb DC, Gorry MC, Preston RA, Furey W, Sossenheimer MJ, Ulrich CD et al. Hereditary pancreatitis is caused by a mutation in the cationic trypsinogen gene. Nat Genet 1996; 14: 141-145.

5. Gorry MC, Gabbaizedeh D, Furey W, Gates Jr LK, Preston RA, Aston CE et al. Mutations in the cationic trypsinogen gene are associated with recurrent acute and chronic pancreatitis. Gastroenterology 1997; 113: 1063-1068.

6. Sahin-Toth M. Human cationic trypsinogen. Role of Asn-21 in zymogen activation and implications in hereditary pancreatitis. J Biol Chem 2000; 275: 22750-22755.

7. Sahin-Toth M, Toth M. Gain-of-function mutations associated with hereditary pancreatitis enhance autoactivation of human cationic trypsinogen. Biochem Biophys Res Commun 2000; 278: 286-289.

8. Chen JM, Montier T, Ferec C. Molecular pathology and evolutionary and physiological implications of pancreatitis-associated cationic trypsinogen mutations. Hum Genet 2001 109: 245-252.

9. Kukor Z, Toth M, Pal G, Sahin-Toth M. Human cationic trypsinogen. $\operatorname{Arg}(117)$ is the reactive site of an inhibitory surface loop that controls spontaneous zymogen activation. J Biol Chem 2002; 277: 6111-6117.

10. Rinderknecht H. Activation of pancreatic zymogens. Normal activation, premature intrapancreatic activation, protective mechanisms against inappropriate activation. Dig Dis Sci 1986; 31: 314-321.
11. Witt $\mathrm{H}$, Luck W, Hennies HC, Classen M, Kage A, Lass $\mathrm{U}$ et al. Mutations in the gene encoding the serine protease inhibitor, Kazal type 1 are associated with chronic pancreatitis. Nat Genet 2000; 25: 213-216.

12. Nathan JD, Romac J, Peng RY, Peyton M, Macdonald RJ, Liddle RA. Transgenic expression of pancreatic secretory trypsin inhibitor-I ameliorates secretagogue-induced pancreatitis in mice. Gastroenterology 2005; 128: 717-727.

13. Rinderknecht. Pancreatic secretory enzymes. In: Go VLW, DiMagno EP, Gardner JD, Lebenthal E, Reber HA, Scheele GA (eds). The Pancreas: Biology, Pathobiology and Disease. 2nd edn. Raven Press: New York, 1993. pp 219-251.

14. Threadgold J, Greenhalf W, Ellis I, Howes N, Lerch MM, Simon P et al. The N34S mutation of SPINK1 (PSTI) is associated with a familial pattern of idiopathic chronic pancreatitis but does not cause the disease. Gut 2002; 50: 675-681.

15. Gaisano HY, Gorelick FS. New insights into the mechanisms of pancreatitis. Gastroenterology 2009; 136: 2040-2044.

16. Steer ML. Search for the trigger mechanism of pancreatitis. Gastroenterology 1984; 86 : 764-766.

17. Brady M, Christmas S, Sutton R, Neoptolemos J, Slavin J. Cytokines and acute pancreatitis. Baillieres Best Pract Res Clin Gastroenterol 1999; 13: 265-289.

18. Kaiser AM, Saluja AK, Sengupta A, Saluja M, Steer ML. Relationship between severity, necrosis, and apoptosis in five models of experimental acute pancreatitis. Am J Physio 1995; 269(5 Pt 1): C1295-C1304.

19. Raraty MG, Connor S, Criddle DN, Sutton R, Neoptolemos JP. Acute pancreatitis and organ failure: pathophysiology, natural history, and management strategies. Curr Gastroenterol Rep 2004; 6: 99-103.

20. Bhatia M, Wallig MA, Hofbauer B, Lee HS, Frossard JL, Steer ML et al. Induction of apoptosis in pancreatic acinar cells reduces the severity of acute pancreatitis. Biochem Biophys Res Comm 1998; 246: 476-483.

21. Mareninova OA, Sung KF, Hong $P$, Lugea A, Pandol SJ, Gukovsky I et al. Cell death in pancreatitis: caspases protect from necrotizing pancreatitis. J Biol Chem 2006; 281: $3370-3381$.

22. Archer $\mathrm{H}$, Jura $\mathrm{N}$, Keller J, Jacobson M, Bar-Sagi D. A mouse model of hereditary pancreatitis generated by transgenic expression of $\mathrm{R} 122 \mathrm{H}$ trypsinogen. Gastroenterology 2006; 131: 1844-1855.

23. Selig L, Sack U, Gaiser S, Kloppel G, Savkovic V, Mossner J et al. Characterisation of a transgenic mouse expressing $\mathrm{R} 122 \mathrm{H}$ human cationic trypsinogen. BMC Gastroenterol 2006; 6: 30 .

24. Colomb E, Figarella C. Comparative studies on the mechanism of activation of the two human trypsinogens. Biochim Biophys Acta 1979; 571: 343-351.

25. Kereszturi E, Sahin-Toth M. Intracellular autoactivation of human cationic trypsinogen mutants causes reduced trypsinogen secretion and acinar cell death. J Biol Chem 2009; 284: 33392-33399.

26. Fernandez-Zapico ME, Mladek A, Ellenrieder V, Folch-Puy E, Miller L, Urrutia R. An $\mathrm{mSin} 3 \mathrm{~A}$ interaction domain links the transcriptional activity of KLF11 with its role in growth regulation. EMBO J 2003; 22: 4748-4758.

27. Baumann B, Wagner M, Aleksic T, von Wichert G, Weber CK, Adler G et al. Constitutive IKK2 activation in acinar cells is sufficient to induce pancreatitis in vivo. J Clin Invest 2007; 117: 1502-1513.

28. Etemad B, Whitcomb DC. Chronic pancreatitis: diagnosis, classification, and new genetic developments. Gastroenterology 2001; 120: 682-707.

29. Nathan JD, Romac J, Peng RY, Peyton M, Rockey DC, Liddle RA. Protection against chronic pancreatitis and pancreatic fibrosis in mice overexpressing pancreatic secretory trypsin inhibitor. Pancreas 2010; 39: e24-e30.

30. Chan YC, Leung PS. Acute pancreatitis: animal models and recent advances in basic research. Pancreas 2007; 34: 1-14.

31. Wildi S, Kleeff J, Mayerle J, Zimmermann A, Bottinger EP, Wakefield L et al. Suppression of transforming growth factor beta signalling aborts caerulein induced pancreatitis and eliminates restricted stimulation at high caerulein concentrations. Gut 2007; 56: 685-692.

32. Fernandes-Alnemri T, Litwack G, Alnemri ES. CPP32, a novel human apoptotic protein with homology to Caenorhabditis elegans cell death protein Ced-3 and mammalian interleukin-1 beta-converting enzyme. J Biol Chem 1994; 269: 30761-30764.

33. Nicholson DW, Ali A, Thornberry NA, Vaillancourt JP, Ding CK, Gallant M et al. Identification and inhibition of the ICE/CED-3 protease necessary for mammalian apoptosis. Nature 1995; 376: 37-43.

34. Criddle DN, Gillies S, Baumgartner-Wilson HK, Jaffar M, Chinje EC, Passmore S et al. Menadione-induced reactive oxygen species generation via redox cycling promotes apoptosis of murine pancreatic acinar cells. J Biol Chem 2006; 281: 40485-40492.

35. Fischer L, Gukovskaya AS, Penninger JM, Mareninova OA, Friess H, Gukovsky I et al. Phosphatidylinositol 3-kinase facilitates bile acid-induced $\mathrm{Ca}(2+)$ responses in pancreatic acinar cells. Am J Physiol Gastrointest Liver Physiol 2007; 292: G875-G886.

36. Halangk W, Lerch MM. Early events in acute pancreatitis. Clin Lab Med 2005; 25: $1-15$

37. Neoptolemos JP, Kemppainen EA, Mayer JM, Fitzpatrick JM, Raraty MG, Slavin J et al. Early prediction of severity in acute pancreatitis by urinary trypsinogen activation peptide: a multicentre study. Lancet 2000; 355: 1955-1960.

38. Raraty M, Ward J, Erdemli G, Vaillant C, Neoptolemos JP, Sutton R et al. Calciumdependent enzyme activation and vacuole formation in the apical granular region of pancreatic acinar cells. Proc Natl Acad Sci USA 2000; 97: 13126-13131. 
39. Kruger B, Albrecht E, Lerch MM. The role of intracellular calcium signaling in premature protease activation and the onset of pancreatitis. Am J Pathol 2000; 157: 43-50.

40. Petersen $\mathrm{OH}$, Gerasimenko OV, Tepikin AV, Gerasimenko JV. Aberrant $\mathrm{Ca}(2+)$ signalling through acidic calcium stores in pancreatic acinar cells. Cell Calcium 2011; 50: 193-199.

41. Quaife CJ, Pinkert CA, Ornitz DM, Palmiter RD, Brinster RL. Pancreatic neoplasia induced by ras expression in acinar cells of transgenic mice. Cell 1987; 48: 1023-1034.

42. Wilkie TM, Brinster RL, Palmiter RD. Germline and somatic mosaicism in transgenic mice. Devl Biol 1986; 118(1): 9-18.

43. Dawra R, Sah RP, Dudeja V, Rishi L, Talukdar R, Garg P et al. Intra-acinar trypsinogen activation mediates early stages of pancreatic injury but not inflammation in mice with acute pancreatitis. Gastroenterology 2011; 141: 2210-2217 e2212.

44. Gaiser S, Daniluk J, Liu Y, Tsou L, Chu J, Lee W et al. Intracellular activation of trypsinogen in transgenic mice induces acute but not chronic pancreatitis. Gut 2011; 60: 1379-1388.

45. Sah RP, Dudeja V, Dawra RK, Saluja AK. Caerulein-Induced Chronic Pancreatitis Does Not Require Intra-Acinar Activation of Trypsinogen in Mice. Gastroenterology 2013; 144: 1076-1085.

46. Raraty MG, Halloran CM, Dodd S, Ghaneh P, Connor S, Evans J et al. Minimal access retroperitoneal pancreatic necrosectomy: improvement in morbidity and mortality with a less invasive approach. Ann Surg 2010; 251: 787-793.

47. Halangk W, Kruger B, Ruthenburger M, Sturzebecher J, Albrecht E, Lippert H et al. Trypsin activity is not involved in premature, intrapancreatic trypsinogen activation. Am J Physiol Gastrointest Liver Physiol 2002; 282: G367-G374.

48. Ji B, Gaiser S, Chen X, Ernst SA, Logsdon CD. Intracellular trypsin induces pancreatic acinar cell death but not NF-kappaB activation. J Biol Chem 2009; 284: 17488-17498.

49. Ji $B$, Logsdon CD. Digesting new information about the role of trypsin in pancreatitis. Gastroenterology 2011; 141: 1972-1975.
50. Griffiths DJ, Venables PJ, Weiss RA, Boyd MT. A novel exogenous retrovirus sequence identified in humans. $J$ Virol 1997; 71: 2866-2872.

51. Brady M, Vlatkovic N, Boyd MT. Regulation of $\mathrm{p} 53$ and MDM2 activity by MTBP. Mol Cell Biol 2005; 25: 545-553.

52. Junqueira LC, Bignolas G, Brentani RR. Picrosirius staining plus polarization microscopy, a specific method for collagen detection in tissue sections. Histochem $J 1979 ; 11$ : 447-455.

53. Booth DM, Murphy JA, Mukherjee R, Awais M, Neoptolemos JP, Gerasimenko OV et al. Reactive oxygen species induced by bile acid induce apoptosis and protect against necrosis in pancreatic acinar cells. Gastroenterology 2011; 140: 2116-2125.

54. Chvanov M, Gerasimenko OV, Petersen OH, Tepikin AV. Calcium-dependent release of NO from intracellular S-nitrosothiols. EMBO J 2006; 25: 3024-3032.

(c) ()ㅇ Cell Death and Disease is an open-access journal published by Nature Publishing Group. This work is licensed under a Creative Commons Attribution-NonCommercialShareAlike 3.0 Unported License. The images or other third party material in this article are included in the article's Creative Commons license, unless indicated otherwise in the credit line; if the material is not included under the Creative Commons license, users will need to obtain permission from the license holder to reproduce the material. To view a copy of this license, visit http://creativecommons.org/licenses/ by-nc-sa/3.0/

Supplementary Information accompanies this paper on Cell Death and Disease website (http://www.nature.com/cddis) 